\title{
Intraaortic Balloon Pump Support During Coronary Angioplasty. Initial Experience
}

\author{
Evandro C.V. Osterne, Gustavo A. Alexim, Vicente P. da Motta, Rosaly M.M. Lins, \\ Eustáquio F. Carvalho, Marcos V. Carneiro, Elio Ribeiro de Morais, Alexandre V. Brick
}

Brasília, DF - Brazil

\begin{abstract}
Objective - To evaluate the use of the intraaortic balloon (IAoB) in association with coronary angioplasty in high-risk patients.

Methods - Fourteen high-risk patients unresponsive to clinical therapy and with formal contraindication to surgical revascularization were treated by coronary angioplasty, most of which was followed by stenting. All procedures were performed with circulatory support with the IAoB. This study reports the early results and the late findings after 12 months of follow-up. Six patients had multivessel coronary disease; of these, four had left main equivalent lesions and two had unprotected left main coronary artery disease, one of whom had severe "endvessel" stenosis and the other was a patient with Chagas" disease with single-vessel lesion. Eleven patients had a left ventricular ejection fraction $<30 \%$.
\end{abstract}

Results - In 100\% of the patients, the procedures were initially successful. Two patients had severe bleeding during the withdrawal of the left femoral sheath. At the end of twelve months, 4 patients were asymptomatic and the others were clinically controlled. There were two late deaths in the $7^{\text {th }}$ and $11^{\text {th }}$ months.

Conclusion - The combined use of the intraaortic balloon pump and percutaneous coronary angioplasty in high-risk patients with acute ischemic syndromes provides the necessary hemodynamic stability to successfully perform the procedures.

Keywords: circulatory support, coronary angioplasty, intraaortic balloon pump.

Hospital das Forças Armadas - Brasília

Mailing address: Evandro C. V. Osterne - Quadra 12 - Bl. U, Casa 35 - Cruzeiro Velho - 70645-000 - Brasília, DF - Brazil.

Received on 10/28/98

Accepted on $4 / 7 / 99$
Interventional cardiology has significantly progressed in the last 20 years, mainly in regard to percutaneous myocardial revascularization techniques ${ }^{1,2}$. The advances in the development of instruments used to perform coronary angioplasty combined with the advent of new devices, such as stents, have allowed the use of this therapy in most patients ${ }^{3,4}$.

The concomitant development of techniques for circulatory support has also occurred, in particular the intraaortic balloon (IAoB), which is being increasingly used in patients with ischemic heart disease ${ }^{5-8}$. The use of the IAoB, which required surgical placement, was initially restricted to cases of cardiogenic shock and preinfarction angina ${ }^{9,10}$. Later, with percutaneous insertion, the complications caused by surgical handling of the femoral artery were greatly reduced, facilitating the use of this technique in intensive care units and, particularly, in catheterization laboratories ${ }^{11}$.

Although widely employed, coronary angioplasty has become prohibitive in patients with severe ventricular dysfunction or in patients with lesions in coronary arteries that irrigate a significant area of viable myocardium.

Thus, the concomitant use of both methods has allowed the performance of percutaneous revascularization in high-risk patients, in which surgery is contraindicated, while achieving adequate circulatory stability ${ }^{12}$.

The purpose of this study was to assess the early experience at our institution with coronary angioplasty performed with circulatory support with the IAoB in highrisk patients.

\section{Methods}

From April 1996 to August 1998, 14 patients with clinical findings of acute coronary syndromes unresponsive to clinical therapy underwent coronary angioplasty with circulatory support with the IAoB. After evaluating each individual case, surgical therapy was contraindicated mainly due to associated complicating factors, such as 
significantly reduced left ventricular function $(\mathrm{EF}<30 \%)$ in 13 patients, severe pulmonary emphysema in 3 patients, and acute renal failure in 3 patients. Four patients were more than 70 years old, and 3 patients had undergone previous revascularization surgery.

In 10 patients, the procedure was complemented by the placement of 12 stents. Every patient gave written consent.

All procedures were performed through the bifemoral approach. We chose the left femoral artery for the implantation of the IAoB and the right femoral artery for the placement of angioplasty catheters.

After the arteries were punctured and the sheaths inserted, the patients received 5,000U of sodium heparin. Subsequently, the IAoB was advanced through a retrograde arterial path with a flexible guide wire up to the correct position, immediately below the origin of the left subclavian artery. Then, the balloon was connected to the module, adjustments in the pressure curve were made and the electrocardiogram was monitored. Our clinic uses Datascope System 90 equipment (Datascope Corp., 15 Law Drive - CN 4011, Fairfield, New Jersey, USA). According to the manufacturer's instructions, the balloons employed had a caliber of $9.5 \mathrm{~F}$ and a volume of $40 \mathrm{cc}$ when inflated, as the patients ranged in height from $1.60 \mathrm{~m}$ to $1.83 \mathrm{~m}$.

A few minutes after the beginning of the counterpulsation, coronary angioplasty was performed, according to routinely used methods.

In patients undergoing stent placement, we followed our routine, which initially consists of precise definition of the lesion, mainly in relation to its extent and diameter of the vessel. A stent/vessel ratio of approximately 1.0 to 1.2 was adopted as ideal. After the liberation of the prosthesis, there must not be any residual lesion hreater than $5 \%$ and it must cover all the lesion/dissection and must not restrict an important branch. Finally, control angiographies in a series of projections and the prescription of medications consisting of ticlopidine $(500 \mathrm{mg} / \mathrm{d}$ for 30 days $)$ and acetylsalicylic acid $(200 \mathrm{mg} / \mathrm{d}$ for 6 months) are required.

Soon after the procedure, the rate of inflation of the balloon was progressively reduced, until its disconnection. The femoral sheaths were kept in place after all the instrumentation was removed.

Subsequently, the patients were referred to the intensive care unit (ICU) for 24-hours. After this period, both femoral sheaths were removed and hemostasis with manual compression, as well as concomitant control of activated clotting time (ACT), was performed.

All patients were considered high-risk patients: their left ventricular ejection fraction (EF) was $<30 \%$, the impaired vessels irrigated more than $50 \%$ of the viable myocardium, they had lesions in the left main coronary artery, with or without protection, or they had lesions equivalent to those of the left main coronary artery.

Almost all patients had very poor left ventricular function $(\mathrm{EF}<30 \%)$, 6 had multivessel lesions, 4 had lesions equivalent to those of the left main coronary artery and 2 had severe lesions in an unprotected left main coronary artery. The 2 remaining patients had single-vessel lesions; 1 had a severe lesion in a final artery and the other had dilated cardiomyopathy as a result of Chagas' disease.

The patients with multivessel disease underwent angioplasty of the culprit artery, which was confirmed by clinical and laboratory tests. These arteries also fulfilled the criterion of irrigating a critical viable myocardial mass (fig. 1). The 2 patients with severe disease of the left main coronary artery received tubular stents. (fig. 2).

The tubular stainless steel stents employed were of the Palmaz-Schatz type, by Johnson and Nir (Sci-Med).

After discharge, the patients were followed up on an outpatient basis or with telephone interviews for 12 months. Exercise testing at 3 months and control angiography at 6 months were not performed in all patients.

\section{Results}

All procedures were successful. There were no cases of hypotension or any sign of circulatory instability. None of the patients reported significant chest pain during the inflation of the angioplasty balloon.

Two patients had significant bleeding at the left inguinal region, in spite of coagulation control. This bleeding was corrected with intravenous protamine, prolonged inguinal compression and blood replacement.

The mean hospital stay was approximately 6 days.

During the 6 months of follow-up, 6 patients showed recurrence of angina pectoris of slight intensity, which was easily controlled with oral drugs. In 7 patients with signs and symptoms of heart failure in addition to symptoms of chest pain before hospitalization, the symptoms recurred and were controlled by changing the oral therapy. Four patients became asymptomatic up to 6 months with the use of anti-platelet agents only. There were two late deaths as a result of sudden death after 7 and 11 months of follow-up.

After 12 months, 7 patients had controlled stable angina, 8 experienced heart failure, which was also medically controlled, and 4 were asymptomatic.

\section{Discussion}

The morphological type of coronary lesion is known to play a major role in the outcome of angioplasty ${ }^{13}$. Calcification, extension and eccentricity of the lesions are known to account for increased incidence of complications during the procedures.

However, in patients with severely affected left ventricular function or in those with coronary lesions in vessels that irrigate a critical mass of viable myocardium, the main factor is intolerance to transient ischemia, determined by occlusion of the angioplasty balloon ${ }^{14,15}$.

The use of the IAoB in these patients has 2 beneficial effects: the $1^{\text {st }}$ occurs as a result of inflation of the balloon and consequent increase of the aortic diastolic pressure, 


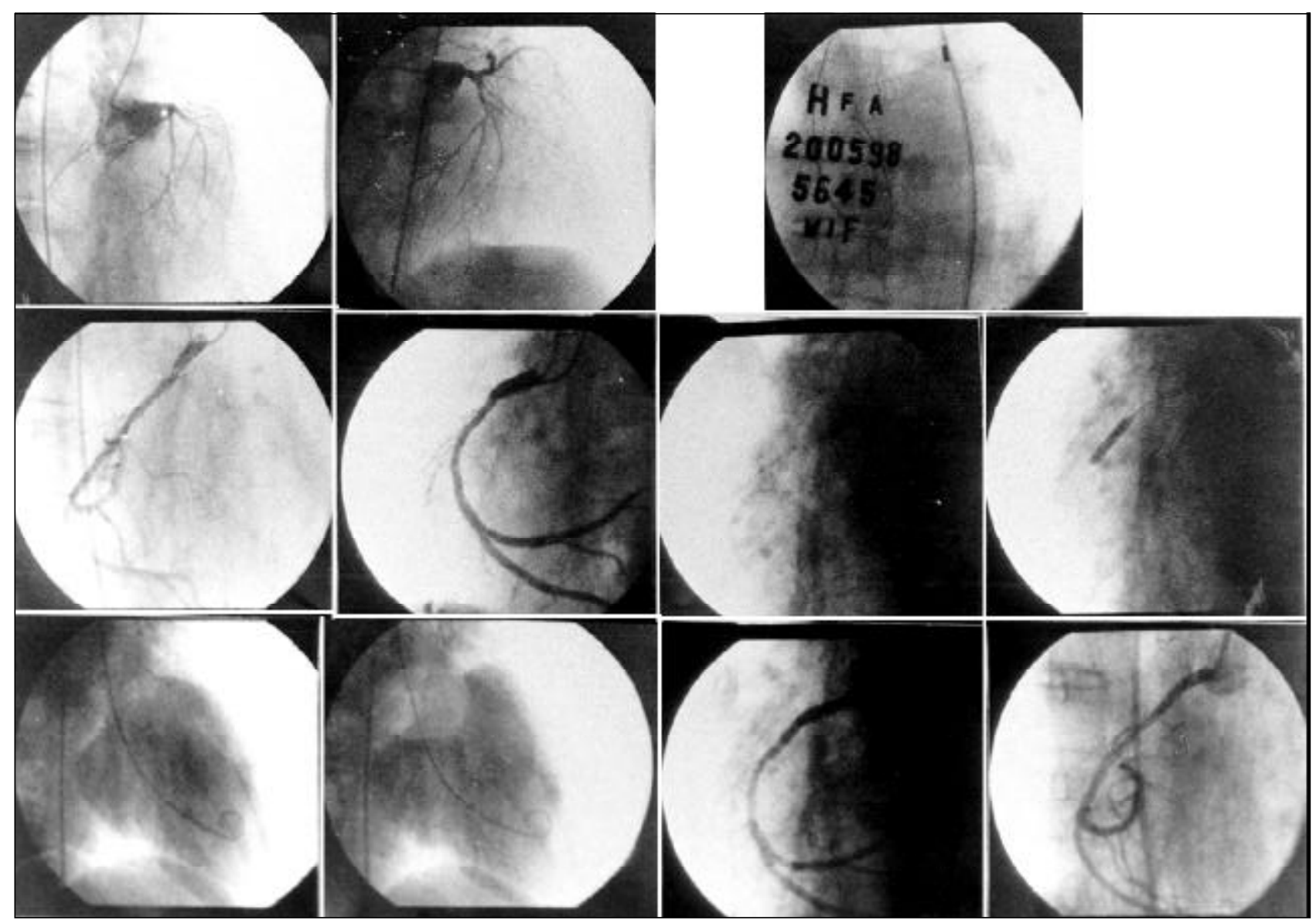

Fig. 1 - A patient with severe diffuse atherosclerosis of the left coronary artery. Severe LV dysfunction. After stenting of the proximal third of the RCA, the clinical findings became stable.

leading to a significant increase in coronary flow; the $2^{\text {nd }}$ occurs as a result of deflation of the balloon, which creates a negative pressure in the descending aorta, significantly reducing the resistance to the left ventricle out flow. Thus, the first effect increases oxygen supply and the second effect reduces oxygen consumption.

Currently, there are several indications for the use of the IAoB in cardiac catheterization laboratories (table I).

First, it is electively used in angioplasties of high-risk patients, as in those in our series. These patients usually have decreased ventricular function and a considerable extent of viable myocardium at risk.

Second, the IAoB is employed when new devices, such as atherectomy catheters, which perform tissular ablation, are used. These devices may cause embolic phenomena during their operation, which may lead to subsequent circulatory instability, depending on the importance of the vessel. Directional atherectomy and the percutaneous extraction catheter may lead to these complications especially in the presence of coronary thrombosis, as occurs in unstable angina and acute myocardial infarction (AMI). Rotational atherectomy (rotablator), however, is the procedure that bears the strongest relation to these complications, as it is the most frequently employed. In approximately $10 \%$ of the cases in which the rotablator is used, the slow-flow and no-reflow phenomena are noted, and they usually persist for hours or days, leading to myocardial dysfunction. If the treated vessel is important and if there is previous ventricular dysfunction, serious consequences may arise. That is why prophylactic implantation of the IAoB in these selected cases is important ${ }^{16,17}$.

Acute coronary occlusion during angioplasty may also lead to circulatory failure when a major vessel is treated. Use of the IAoB for this type of complication offers the beneficial effects of hemodynamic stability and increased perfusion through the occluded vessel ${ }^{18}$.

Unstable angina, as well as AMI and its complications, are particularly improved by aortic counterpulsation.

Currently, almost all cases of unstable angina resolve with the use of medications such as beta-blockers, antiplatelet agents, heparin and new substances, such as abciximab. However, in some cases, even the combined use of these drugs does not lead to stabilization of clinical findings. Refractoriness to medication and its potential risk interfere with the invasive management of these patients with the IAoB. Thus, after the patient is hemodynamically stable, elective coronary angiography is performed. The latter will show the coronary anatomy and guide the management strategy ${ }^{19}$. 

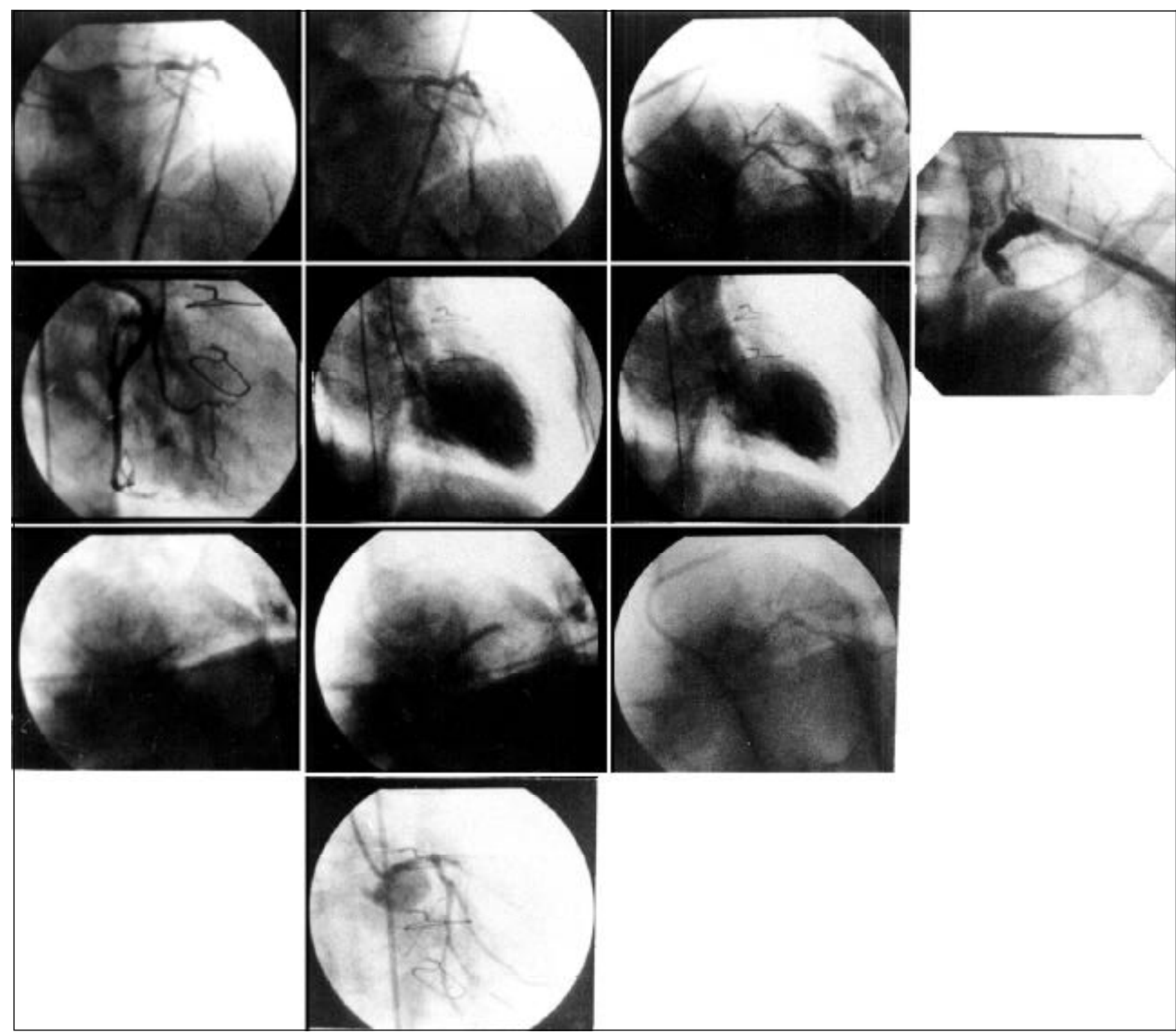

Fig. 2 - Severe diffuse lesion of the "unprotected" left main coronary artery, treated with tubular stenting.

In AMI, the reduction of the afterload caused by the IAoB attenuates the effects of the decreased local coronary perfusion and increases the blood flow through the occluded artery ${ }^{20}$. Thus, the use of this procedure combined with thrombolytic therapy seems to significantly reduce the incidence of reocclusion of the culprit artery of the infarction. The fact that the incidence of bleeding complications is not increased is also of note ${ }^{21,22}$.

Primary or rescue coronary angioplasty has similar effects ${ }^{23,24}$. A series of reports have shown the benefit of the IAoB in reducing the incidence of post-angioplasty reocclusion. Many clinics use the $\mathrm{IAoB}$ routinely in these 2 scenarios, when the infarction is associated with signs of severe left ventricular dysfunction or when the culprit artery remains occluded in spite of all measures taken.

In cardiogenic shock, sole use of the IAoB has not lead to a significant improvement in the prognosis. Concomitant surgical or percutaneous revascularization is required ${ }^{23-25}$.

The same is true for the mechanical complications of
AMI. In addition to correction of the ventricular septal defect (VSD) or replacement of the mitral valve, revascularization is also indispensable ${ }^{26}$. The IAoB temporarily provides the adequate hemodynamic stabilization required for the complete treatment of the patients.

\begin{tabular}{|c|}
\hline Table I - Intraaortic balloon in the cardiac catheterization unit \\
\hline $\begin{array}{l}1 \text { - Elective use } \\
\text { - "High-risk" angioplasty } \\
\text { - Atherectomies (rotablator) } \\
2 \text { - Emergencies } \\
\text { - Unstable angina } \\
\text { - Postangioplasty acute occlusion } \\
\text { - Acute myocardial infarction with thrombolytic agents } \\
\text { Primary or rescue coronary angioplasty } \\
\text { Cardiogenic shock } \\
\text { Mechanical complications (MI, SVD) } \\
\text { - Nonischemic mitral regurgitation } \\
\text { Patients waiting for heart transplantation }\end{array}$ \\
\hline
\end{tabular}


The IAoB is also employed in nonischemic emergencies, such as mitral regurgitation caused by idiopathic rupture of chordae tendineae or in acute bacterial endocarditis. In these patients with previous ventricular function within the normal range, reduction in the afterload leads to reduction in the amplitude of the "V wave" and of the pulmonary capillary wedge pressure.

Finally, the IAoB is being increasingly used while patients wait for heart transplantation. Patients with heart failure refractory to therapy usually require circulatory support for several weeks until a heart is available for transplantation. Considering the different devices for circulatory support, the IAoB is the most adequate, as it is user-friendly and is associated with fewer side effects.

Lately, the complications associated with the use of the IAoB have been extensively examined. The overall incidence is around $10 \%$ of the cases and, currently, severe ischemia of the lower limbs occurs in less than $1 \%$ of the procedures ${ }^{27,28}$.

Patients most likely to present with complications are those with severe hypertension, diabetes, females and, in particular, those with peripheral vascular disease.

Recently, a progressive decrease in the number of complications has been noted. This decrease has resulted from the reduction in the caliber of the balloons, as well as from the use of instruments with increased flexibility and percutaneous introduction without the use of sheaths.

In conclusion, the availability of the IAoB has stimulated high-risk procedures, with hemodynamic stability and a low rate of complications. Larger studies are needed to determine the cost-benefit ratio of this procedure in this group of patients.

\section{References}

1. Detre KM, Holmes Dr Jr, Holubkov R, et al and NHLBI PTCA Registry: Incidence and consequences of periprocedural occlusion (1985-1986 Registry). Circulation 1990: 82: 739.

2. Safian R, Freed M, Lichtenberg A, et al. Usefulness of percutaneous transluminal coronary angioplasty after new device coronary interventions. Am J Cardiol 1994; 73: 642-6.

3. Fishman DL, Baim DS, Leon MB, et al. A randomized comparision of coronary stent placement and balloon angioplasty in the treatment of coronary artery disease. N Engl J Med 1994; 331: 496-501.

4. Colombo A, Hall P, Davies R, et al. Results of intravascular ultrasound guided coronary stenting without subsequent anticoagulation. J Am Coll Cardiol 1994; 23: 335A.

5. Hanloser PB, Schenk WG, Gallow E, et al. Hemodynamics of conterpulsation. J Thorac Cardiovasc Surg 1966; 51: 366.

6. Maroko PR, Bernstein EF, Libby P, et al. Effects of intraortic ballon conterpulsation on the severity of myocardial ischemic injury following coronary occlusion. Conterpulsation and myocardial injury. Circulation 1972; 45: 1150-9.

7. Davies R, Laks H, Berger H, et al. Follow-up radionuclide assessment of left ventricular function and perfusion in patients requiring intraortic pump balloon to wean from cardiopulmonary bypass. Am J Cardiol 1980; 45: 488.

8. Aguirre FV, et al. Intraortic balloon pump support during high-risk coronary angioplasty. Cardiology 1994; 84: 175-86.

9. Wolvek $S$. The evolution of the intraortic balloon. The Datascope contribution. J Biomater Appl 1989; 3: 527-42.

10. Kantrowitz A, Tjonneland S, Freed PS, Philips SJ, et al. Initial clinical experience with intraortic balloon pumping in cardiogenic shock. JAMA 1968; 203: $135-40$

11. Nash IS, Lorell BH, Fishman RF, et al. A new technique for sheatless percutaneous intraortic balloon catheter inserction. Cathet Cardiovasc Diagn 1991; 23: 57-60.

12. Alcan KE, Stertzer SH, Wallsh E, et al. The role of intraortic balloon conterpulsation in patients undergoing percutaneous transluminal coronary angioplasty. Am Heart J 1983; 105: 527-30.

13. Ellis SG, Roubin GS, King SB, et al. Angiographic and clinical predictors of acute closure after native vessel coronary angioplasty. Circulation 1988; 77: 372.

14. Anwar A, Mooney MR, Stertzer SH, et al. Intraortic balloon conterpulsation support for eletive coronary angioplasty in the setting of poor left ventricular function. A two center experience. J.Inv Cardiol 1990; 2: 175-80.

15. Hartzler GO, Rutheford BD, Mc Conahay DR, et al. "High-risk"percutaneous transluminal coronary angioplasty.Am J Cardiol 1988; 61: 33 G-37 G.
16. Ishihara M, Sato H, Tateishi $\mathrm{H}$, et al. Effects of intraortic balloon pump therapy on coronary hemodynamics after coronary angioplasty in patients with acute myocardial infarction. Am Heart J 1992; 124: 1133-8.

17. Serruys PW, Wijns W, Vandenbrand M, et al. Left ventricular performance,regional blood flow,wall moctionand lactate metabolism during transluminal angioplasty.Circulation 1984; 70: 25-36.

18. Ferguson TB, Muhlbaiier LH, Salas DL, et al. Coronary bypass grafting after failed eletive and failed emergent percutaneous angioplasty. J Thorac Cardiovasc Surg 1988; 95: 761-72.

19. Fuchs RM, Brin KP, Brinker JA, et al. Augmentation of regional coronary blood flow by intraortic balloon conterpulsation in patients with unstable angina. Circulation 1983; 68: 117-23.

20. O Rourke MF, Norris RM, Campbell TJ, et al. Randomized controlled trial of intraortic balloon conterpulsation in early myocardial infarction with acute heart failure. Am J Cardiol 1981; 47: 815-20.

21. Goodwin M, Norris RM, Sander SS, et al. Safety of intraortic balloon conterpulsation in patients with acute myocardial infarction receiving streptokinase intravenously. Am J Cardiol 1989; 64: 937-8.

22. Gurbel PA, Godart J, Anderson RD, et al. Arterial diastolic pressure augmentation by intraortic balloon conterpulsation enhances the onset of coronary artery reperfusion by thrombolitic therapy.Circulation 1994; 89: 361-5.

23. Grines CL, Browne KR, Marco L, et al. A comparision of prmary angioplasty with thrombolitic therapy for acute myocardial infarction. N Engl J Med 1993; 328: 673-9.

24. Griffin J, Grines CL, Browne KR, et al. A prospective, randomized trial evaluation of the profilatic use of balloon pumping in high risk myocardial infarction patients: PAMI 2. J Am Coll Cardiol 1995; 25: 86A

25. De Wood MA, Notshe RN, Hensley GR, et al. Intraortic balloon conterpulsation with or without reperfusion for myocardial infrction shock. Circulation 1980; 61: 1105-12.

26. Gold HK, Leinbach RC, Sanders CA, et al. Intraortic balloon pump therapy for ventricular septal defect or mitral regurgitation complicating acute myocardial infarction. Circulation 1973; 47: 1191-6.

27. Gottlieb SO, Brinker JA, Barkon M, et al. Identification of patients at high risk for complications of intraortic balloon conterpulsation: a multivariate risk factor analysis. Am J Cardiol 1984; 53: 1135-9.

28. Kantrowitz A, Wasfie T, Rubenfire M, et al. Intraortic balloon pump therapy 1967 through 1982: analysis of complications in 733 patients. Am J Cardiol 1986; 57: 976-83. 